\title{
Phthalate Esters Detected in Various Water Samples and Biodegradation of the Phthalates by Microbes Isolated from River Water
}

\author{
Kiyomatsu Hashizume, ${ }^{*}$ Jo Nanya, Chitose Toda, Teruyo Yasu, Hideo Nagano, and Nakao Kojima \\ Faculty of Pharmacy, Meijo University, 150 Yagotoyama, Tempaku-ku, Nagoya 468-8503, Japan. \\ Received July 26, 2001; accepted December 3, 2001
}

\begin{abstract}
Phthalate esters (PEs), especially di-n-butyl phthalate (DBP) and di-(2-ethylhexyl) phthalate (DEHP) were detected in various water samples such as river water, well water and tap water. On degradation tests of PEs, Tempaku River water degraded almost $100 \%$ of diethyl phthalate (DEP), di-isobutyl phthalate and DBP, and approximately 70\% of DEHP. All eight isolates from Tempaku River water (R1-R7, D1) did not degrade dimethyl phthalate (DMP), but showed biodegrading ability for the other PEs. The DBP-degrading ability was particularly high for the isolates R1-R3 and D1 of Acinetobacter lwoffii. Crude enzyme solutions prepared from bacterial cells of these isolates showed a higher degrading activity for DEHP compared with that for microbiallydegradable DBP. Particularly high DEHP-degrading activity was found for crude enzyme solutions of the isolate D1. As metabolites from the river water and bacterial isolates, DMP and an unknown diester were produced from DEP. DMP, DEP, monomethyl phthalate, monobutyl phthalate (MBP) and an unknown diester were produced from DBP. DBP, DEP, DMP and an unknown diester were produced from DEHP. As metabolites by the crude enzyme solutions, DMP, MBP and an unknown diester derivative were produced from DBP. DBP, mono(2-ethylhexyl) phthalate and an unknown diester derivative were produced from DEHP. Diesters with shortened alkyl carbon chains were also found as metabolites by the isolates and their crude enzyme solutions. The results suggest that the alkyl chains in the diesters are also decomposed in addition to monoester formation from DBP or DEHP at the first step reported for animals and some types of bacteria.
\end{abstract}

Key words phthalate ester; biodegradation; metabolite; DEHP; river water; microbial isolate

Phthalate esters (PEs) are used as plasticizers for plastics in a broad range of products, and produced in large quantities. Therefore, PEs are widely diffused in the atmosphere and hydrosphere. There have been many reports on the hepatotoxicity, testicular atrophy, teratogenicity and carcinogenicity as related to PEs. ${ }^{1-6)}$ Recently, di- $n$-butyl phthalate (DBP) and di-(2-ethylhexyl) phthalate (DEHP) have in particular been attracting attention as being suspects in disrupting the endocrine system. ${ }^{7-10)}$

PEs are considered to be biodegradable and having low bioaccumulation. However, they have been constantly detected in air, water and fish since the 1970's, although they have been decreasing since 1980. DEHP was detected in river water and aquatic biological systems based on the survey performed by the Environment Agency in 1999. ${ }^{11)}$ Since some aquatic microorganisms are widely involved in degradation of pollutants in water systems, it is worthwhile to find microorganisms that can biodegrade PEs for remediation of water systems. In this study, various water samples such as tap water and river water were examined for the level of PE pollution. Then the biodegradation products and pathways of PEs were investigated using the river water, bacterial isolates from the river water, and crude enzyme solutions prepared from the isolates. Also, the use of the isolates is discussed for restoration of the environment polluted by PEs.

\section{MATERIALS AND METHODS}

Chemicals Dimethyl phthalate (DMP, $>99.5 \%$ ), diethyl phthalate (DEP, $>99.5 \%$ ), DBP $(99.5 \%)$, di-isobutyl phthalate (DIBP, 99.5\%), DEHP (>99.5\%) of standard grade and methanol $\left(\mathrm{CH}_{3} \mathrm{OH}\right) 1000, n$-hexane 1000 , ethyl acetate 1000 suitable for pesticide residue-PCB analysis, acetonitrile $\left(\mathrm{CH}_{3} \mathrm{CN}\right)$ and trifluoroacetic acid (TFA) suitable for HPLC and trichloroacetic acid (TCA) suitable for biochemical analysis, 2-amino-2-hydroxymethyl-1,3-propanediol (Tris) of special grade, 2,2-bis(4-hydroxyphenyl)propane (bisphenol A) and polyoxyethylene(10)octylphenyl ether (Triton X-100) were purchased from Wako Pure Chemical Industries Co., Ltd. (Osaka, Japan). Monoethyl phthalate (MEP), monobutyl phthalate (MBP) and mono(2-ethylhexyl) phthalate (MEHP) were purchased from Tokyo Chemical Industries Co., Ltd. (Tokyo, Japan). D-Glucose-6-phosphate disodium (G-6-P), nicotinamide adenine dinucleotide phosphate reduced form (NADPH) and nicotinamide-adenine dinucleotide reduced form (NADH) were obtained from Oriental Yeast Co., Ltd. (Tokyo, Japan) and nutrient broth (NB) was obtained from Difco Laboratories (Detroit, MI, U.S.A.). All the other chemicals used were of guaranteed reagent grade.

Detection of PEs. Water Samples River water samples were collected from Otokiki Bridge (mid-Nagoya City area, Japan) and Chidori Bridge (near Ise Bay) on the Tempaku River, Inuyama Bridge on the Kiso River (Inuyama, Aichi, Japan) and Kumozu River (Misugi Village, Mie, Japan). Well water and tap water were collected at Meijo University, Tempaku-ku and other tap water in house was collected at Moriyama-ku, Nagoya City. Distilled water was prepared using a distillator, Autostill WG35 (Yamato, Tokyo, Japan). Distilled water was also treated according to the method described for total organic carbon (TOC) measurements. ${ }^{15}$ Mineral water and deionized water for volatile organic compounds (VOC) measurement were purchased from commercial sources.

Method of Determination All glass tools were washed with $n$-hexane or $\mathrm{CH}_{3} \mathrm{OH}$, then heated at $200^{\circ} \mathrm{C}$ for $4 \mathrm{~h}$ before use. $\mathrm{NaCl}$ and anhydrous sodium sulfate were washed with $n$-hexane-ethyl acetate $(8: 2)$ and burned for $5 \mathrm{~h}$ before use. PEs and bisphenol $\mathrm{A}$ in water samples were extracted 
with $n$-hexane-ethyl acetate $(8: 2)$ and determined by a gas chromatograph (GC) equipped with a flame ionization detector (FID) under operating conditions as described in the section of Instruments and Conditions of Analysis.

Extraction Method-1: For large volume (total $5000 \mathrm{ml}$ ) samples, to a $2000-\mathrm{ml}$ separatory funnel, $1000 \mathrm{ml}$ of water sample and $50 \mathrm{~g}$ of $\mathrm{NaCl}$ were added, and extracted with 300 $\mathrm{ml}$ of $n$-hexane-ethyl acetate $(8: 2)$. This procedure was repeated for extraction of maximal volume $5000 \mathrm{ml}$ of water samples. The organic layer was dehydrated over anhydrous sodium sulfate and concentrated below $30^{\circ} \mathrm{C}$ in vacuo. The oily residue was dissolved in a small amount of $n$-hexane, and applied to GC. A blank operation was performed without adding water samples. The recoveries of DBP and DEHP added were 97 and $95 \%$, respectively. The detection limit was $0.03 \mu \mathrm{g} / 1$. This method was used otherwise stated.

Extraction Method-2: For relatively small volume $(950 \mathrm{ml})$ samples, to a $1000-\mathrm{ml}$ volumetric flask, $950 \mathrm{ml}$ of water sample, $150 \mathrm{~g}$ of $\mathrm{NaCl}$ and $25 \mathrm{ml}$ of $n$-hexane-ethyl acetate $(8: 2)$ were added, and stirred with a glass stirrer bar for $4 \mathrm{~h}$ to maximize the extraction. After the solvent was evaporated, the oily residue was dissolved in a small amount of $n$-hexane, and applied to GC. The recoveries of DBP and DEHP added were 90 and $47 \%$, respectively. The detection limit was 0.05 $\mu \mathrm{g} / \mathrm{l}$.

Biodegradation Test and Measurement of Enzymatic Degrading Activity. Samples Biodegradation by river water was tested using the Tempaku River water collected in November 1999. Measurement of PE biodegradation by bacteria and PE enzymolysis by bacterial cell-free extracts were performed using the isolates R1-R7, isolated from Tempaku River water and the isolate D1 from the Tempaku River water cultured with diazinon. The isolates have been characterized as follows: the isolates $\mathrm{R} 1-\mathrm{R} 7$ show low degradability to organophosphorus insecticides, fenitrothion and diazinon, the isolate D1 strongly degrade the insecticides, and $\mathrm{R} 1-\mathrm{R} 7$ are also able to degrade diphenylether herbicide, chlornitrofen, but D1 can not degrade the herbicide. ${ }^{12}$ )

Biodegradation Test The biodegradation of PEs and bisphenol A by the river water and bacterial isolates were tested as previously reported ${ }^{13)}$ with a minor modification of the Handai Method. ${ }^{14)}$ Each test chemical was added at a final concentration of $20 \mu \mathrm{g} / \mathrm{ml}$. The residual test chemicals were quantified under the GC-conditions shown in the section of Instruments and Conditions for Analyses.

Measurement of Enzymatic Degrading Activity For measurement of enzymatic degrading activity, supernatant was prepared by centrifugation $(105000 \times \boldsymbol{g}$ for $2 \mathrm{~h})$ of the isolate lysate obtained by the freeze-thawing method as previously reported ${ }^{13)}$ and used as a crude enzyme solution. After the substrates, DBP and DEHP (final concentration, 40 $\mathrm{nmol} / \mathrm{ml}$ ), were incubated with $0.5 \mathrm{ml}$ of the crude enzyme (final protein concentration, $1 \mathrm{mg} / \mathrm{ml}$ ) in $90 \mathrm{~mm}$ Tris- $\mathrm{HCl}$ buffer ( $\mathrm{pH}$ 7.4) with or without the NADPH generating system at $37^{\circ} \mathrm{C}, 30 \%$ TCA solution $(0.1 \mathrm{ml})$ was added to stop the reaction. The reaction mixture was extracted with $1 \mathrm{ml}$ of $n$-hexane-ethyl acetate $(8: 2)$, and the test chemicals were quantified as described in the section Instruments and Conditions for Analyses.

Detection of Metabolites The solutions used for the biodegradation test by the isolates and the crude enzymes were extracted with $n$-hexane-ethyl acetate $(8: 2)$ or 10 -fold volume of $\mathrm{CH}_{3} \mathrm{OH}$, and the organic solvent was evaporated. The residues were analyzed by GC and HPLC to confirm the presence of metabolites before and after methyl-esterification.

Instruments and Conditions for Analyses GC analyses were carried out with a Shimadzu model GC-14B equipped with an FID, Shimadzu model AOC-20i auto injector and Chromatopac C-R6A. HPLC analyses were carried out with a JASCO system comprising of pump PU-986 equipped with UV/VIS detector UV-970, column oven 860-C, Chromatocorder 11 and degasser DC-980-50. TOC analyses were carried out with a Shimadzu total organic carbon analyzer TOC500.

GC Conditions: For detection of PEs: Column, silicone OV-17 5\% Uniport HP 60/80 (3.2 mm i.d. $\times 2 \mathrm{~m})$; column temperature program, from $150^{\circ} \mathrm{C}(1 \mathrm{~min})$ to $240^{\circ} \mathrm{C}(10$ min) at $3{ }^{\circ} \mathrm{C} / \mathrm{min}$; injector and detector temperatures, $260^{\circ} \mathrm{C}$. For DEP and DBP: column, silicone OV-17 5\% Uniport HP $80 / 100$ (3 mm i.d. $\times 2 \mathrm{~m}$ ); column temperature, $190^{\circ} \mathrm{C}$; injector and detector temperatures, $210^{\circ} \mathrm{C}$. For DEHP: column, silicone OV-17 5\% Uniport HP 60/80 (3.2 mm i.d. $\times 2 \mathrm{~m})$; column temperature, $240^{\circ} \mathrm{C}$; injector and detector temperatures, $260^{\circ} \mathrm{C}$.

HPLC Conditions: Analytical column, Develosil ODS-5 $\left(4.6 \mathrm{~mm}\right.$ i.d. $\times 250 \mathrm{~mm}$ ); column temperature, $40^{\circ} \mathrm{C}$; flow rate, $1 \mathrm{ml} / \mathrm{min}$; mobile phase, a) $0.05 \%$ TFA- $60 \% \mathrm{CH}_{3} \mathrm{CN}$ and b) $0.05 \%$ TFA- $40 \% \quad \mathrm{CH}_{3} \mathrm{CN}$. Preparative column, Wakosil $10 \mathrm{C} 18(10 \mathrm{~mm}$ i.d. $\times 250 \mathrm{~mm})$; column temperature, $40{ }^{\circ} \mathrm{C}$; flow rate, $2 \mathrm{ml} / \mathrm{min}$; mobile phase, c) $0.05 \%$ TFA$80 \% \mathrm{CH}_{3} \mathrm{CN}$ and d) $0.05 \%$ TFA- $-60 \% \mathrm{CH}_{3} \mathrm{CN}$.

\section{RESULTS AND DISCUSSION}

Detection of PEs in Water PEs, in particular DBP and DEHP, were detected in river water, well water and tap water and even in the mineral water although they were in small amounts (Table 1).

A clean water cartridge with active charcoal for home use removed approximately $80 \%$ of DBP in tap water processed at the beginning. However, elimination capacity decreased after filtering 3001 of tap water the volume assumed as the volume of use for a month. Capacity of chlorine elimination in the cartridge did not decrease even after filtering the same volume of water used for the DBP test. Increase of DBP and DEHP in filtered water might be due to their release from the filter charcoal saturated with PEs in tap water (Table 2).

PEs were also detected in the distilled water prepared using a laboratory distillation system, redistilled water prepared using a glass distillation apparatus, redistilled water processed for $\mathrm{TOC}^{15)}$ and commercially-available water special for VOC determination (Table 3).

According to the reports, ${ }^{1,15)}$ environmental diffusion of PEs has decreased since the 1970's. Ingestion of PEs via foods decreased because they have not been used in plastic for food application in Japan. ${ }^{16)}$ However, PEs were detected in water used in daily life as shown above, indicating that PEs are constantly ingested via drinking water. PEs were detected even in distilled water commonly used in laboratories and redistilled water processed for TOC. It is difficult to eliminate PEs, which could be contaminated from the air 
Table 1. Contents of PEs in the Water Samples

\begin{tabular}{|c|c|c|c|c|c|c|}
\hline \multicolumn{2}{|c|}{ Sampling } & \multicolumn{5}{|c|}{ Concentration $(\mu \mathrm{g} / \mathrm{l})$} \\
\hline Site & Date & DMP & DEP & DIBP & DBP & DEHP \\
\hline \multicolumn{7}{|l|}{ Tempaku River } \\
\hline Otokiki & July/1998 & $\mathrm{ND}^{b)}$ & ND & ND & 3.34 & 0.97 \\
\hline Bridge & Nov./1999 $\left.{ }^{a}\right)$ & ND & ND & ND & 0.29 & ND \\
\hline Chidori & July/1998 & ND & 0.03 & ND & 3.90 & 1.83 \\
\hline Bridge & Nov./1999 & ND & ND & ND & 0.55 & ND \\
\hline Kiso River & Feb./2000 & ND & ND & ND & 0.51 & 0.99 \\
\hline Kumozu River & Aug./1999 & & & & & \\
\hline Point-1 & & ND & ND & ND & 1.85 & ND \\
\hline-2 & & ND & ND & ND & 2.33 & 0.79 \\
\hline-3 & & ND & ND & ND & 2.59 & 0.66 \\
\hline-4 & & ND & ND & ND & 3.32 & 0.43 \\
\hline Well water & Nov./1998 & & & & & \\
\hline University & & ND & 0.08 & 0.11 & 2.29 & 0.78 \\
\hline \multicolumn{7}{|l|}{ Tap water } \\
\hline House & Nov./1998 & ND & ND & ND & 1.53 & 3.63 \\
\hline \multirow[t]{6}{*}{ University } & Oct./1998 & 0.08 & 0.02 & ND & 1.68 & 5.22 \\
\hline & Nov./1998 & ND & 0.05 & ND & 4.03 & 0.19 \\
\hline & Dec./1998 & ND & ND & ND & 0.91 & 0.94 \\
\hline & April/1999 & ND & ND & ND & 9.26 & 1.64 \\
\hline & April/1999 & ND & ND & ND & 2.41 & ND \\
\hline & Feb./2000 & ND & ND & ND & 0.57 & 0.62 \\
\hline Mineral water $I^{a)}$ & & ND & ND & ND & 0.21 & ND \\
\hline $\mathrm{II}^{a)}$ & & ND & ND & ND & 0.19 & ND \\
\hline II & & ND & ND & ND & 0.52 & 0.42 \\
\hline
\end{tabular}

a) Treated by the extraction method-2 (others were by the extraction method-1). b) ND: Not detected.

Table 2. Elimination of PEs in the Tap Water by Water Filtration Cartridge

\begin{tabular}{|c|c|c|c|c|c|}
\hline \multirow{2}{*}{ Water sample } & \multicolumn{3}{|c|}{ Concentration $(\mu \mathrm{g} / 1)$} & \multirow{2}{*}{$\begin{array}{c}\text { TOC } \\
(\mathrm{mg} / \mathrm{l})\end{array}$} & \multirow{2}{*}{$\underset{(\mathrm{mg} / \mathrm{l})}{\text { Residual }} \mathrm{Cl}_{2}$} \\
\hline & DEP & DBP & DEHP & & \\
\hline Before filtration & $\mathrm{ND}^{a)}$ & 9.26 & 1.64 & 2.29 & 0.1 \\
\hline After 1.5-1 filtration & ND & 3.03 & ND & 2.21 & 0 \\
\hline Before filtration & ND & 2.41 & ND & 1.65 & 0.1 \\
\hline After $300-1$ filtration & ND & 6.69 & 0.56 & 1.26 & 0 \\
\hline
\end{tabular}

a) ND: Not detected.

Table 3. Elimination of PEs in the Laboratory Water by Distillation and Chemical Treatment

\begin{tabular}{lccccc}
\hline \hline \multirow{2}{*}{ Water sample } & \multicolumn{5}{c}{ Concentration $(\mu \mathrm{g} / \mathrm{l})$} \\
\cline { 2 - 6 } & DMP & DEP & DIBP & DBP & DEHP \\
\hline Distilled-I & 0.10 & 0.06 & 1.07 & 1.24 & 4.21 \\
Redistilled & ND $^{c)}$ & 0.14 & 0.57 & 3.28 & 0.93 \\
Treated for TOC & ND & ND & ND & 4.16 & ND \\
Retreated for TOC $^{a)}$ & ND & ND & ND & 1.80 & ND \\
${\text { Water for } \text { VOC }^{b)}}^{\text {ND }}$ & ND & ND & 10.58 & ND
\end{tabular}

a) Treated by the extraction method-2 (others were by the extraction method-1). b) Commercially-available. $c$ ) ND: Not detected.

during long-term exposure. Therefore, special caution should be taken for experimental use of water in laboratories.

Degradation of PEs. Biodegradation by Tempaku River Water In Table 4, biodegradation data are shown for PEs and bisphenol A using the Tempaku River water. Both water samples collected at Otokiki Bridge and Chidori Bridge degraded almost $100 \%$ of DEP, DIBP and DBP and about $70 \%$
Table 4. Biodegradation of Chemicals by Tempaku River Water

\begin{tabular}{ccccccc}
\hline \hline \multirow{2}{*}{$\begin{array}{c}\text { Sampling } \\
\text { site }\end{array}$} & DMP & DEP & DIBP & DBP & DEHP & Bisphenol A \\
\cline { 2 - 6 } & & & & & \\
& $49.3^{a)}$ & $87.6^{a)}$ & $100^{a)}$ & $98.8^{a)}$ & 73.5 & 7.9 \\
\hline $\begin{array}{c}\text { Otokiki Bridge } \\
\text { Chidori Bridge }\end{array}$ & 100 & $100^{a)}$ & $100^{a)}$ & 98.8 & 68.1 & 45.8 \\
\hline
\end{tabular}

An aliquot (100 $\mu \mathrm{g}$ of each) of DMP, DEP, DIBP, DBP, DEHP or bisphenol A was added to $5 \mathrm{ml}$ of $1 / 10 \mathrm{NB}$ medium containing Tempaku River water and cultured at $25^{\circ} \mathrm{C}$ for $7 \mathrm{~d}$. a) Metabolites were detected by GC in the medium after cultivation.

Table 5. Biodegradation of Chemicals by Isolates from River Water

\begin{tabular}{ccccccc}
\hline \hline & \multicolumn{5}{c}{ Biodegradability (\%) } \\
\cline { 2 - 7 } Isolate & DMP & DEP & DBP & DIBP & DEHP & Bisphenol A \\
\cline { 2 - 7 } & & & & & & \\
R1 & 0 & $\left.44.4^{a}\right)$ & $\left.65.1^{a}\right)$ & 92.4 & 6.7 & 1.5 \\
R2 & 0 & $42.6^{a}$ & 49.0 & 72.2 & 35.0 & 19.1 \\
R3 & 0 & $18.2^{a)}$ & $100^{a}$ & 26.3 & 20.0 & 0 \\
R4 & 0 & 61.2 & 98.3 & 79.2 & 17.6 & 11.5 \\
R5 & 0 & 13.2 & 64.8 & 21.9 & 15.0 & 3.5 \\
R6 & 0 & 4.3 & 2.1 & 0 & 46.1 & 0.2 \\
R7 & 0 & 19.6 & 2.5 & 13.1 & 4.4 & 35.1 \\
D1 & 0 & 28.8 & 100 & 0 & 18.3 & 20.1 \\
\hline
\end{tabular}

An aliquot (100 $\mu \mathrm{g}$ of each, except bisphenol A, $200 \mu \mathrm{g})$ of DMP, DEP, DBP, DIBP, DEHP or bisphenol A was added to $5 \mathrm{ml}$ of $1 / 10 \mathrm{NB}$ in test tube and cultured with isolate at $25^{\circ} \mathrm{C}$ for $7 \mathrm{~d}$, respectively. Isolates R1-R4 and D1: Acinetobacter lwoffii, isolate R7: Pseudomonas alcaligenes. a) Metabolites were detected by GC in the medium after cultivation.

of DEHP. Several new peaks of metabolites in each culture broth were detected by HPLC. The retention times $\left(t_{\mathrm{R}}\right.$ 's $)$ of one of the DEP metabolites and one of the DBP metabolites were consistent with those of DMP and MBP, respectively. Biodegradation of DMP and bisphenol A varied greatly among water samples collected at different sites. The water collected at Otokiki Bridge and Chidori Bridge degraded about 50 and $100 \%$ of DMP, respectively, and approximately 8 and $46 \%$ of bisphenol A, respectively.

Biodegradation by Bacterial Isolates The results of biodegradation tests of PEs and bisphenol A by the isolates $\mathrm{R} 1-\mathrm{R} 7$ from the Tempaku River water and the isolate D1 from the Tempaku River water cultured with diazinon are shown in Table 5. DMP was not degraded by the isolates. Other PEs were relatively degradable. Biodegradability of DBP was high when incubated with the isolates R1-R4 and D1 of Acinetobacter lwoffii and the isolate R5. DEHP was degraded $46 \%$ by the isolate R6. The isolate R7 (Pseudomonas alcaligenes) showed highest biodegradability of bisphenol $\mathrm{A}$ in the eight isolates tested, although it was at most $35 \%$. Bisphenol A was also degraded by the isolates R2, R4 and D1 (Table 5).

Time-Courses in DBP Biodegradation by Isolate R3 The time-courses of degradation of DBP by the bacterial isolate R3 is shown in Fig. 1. On day 2, two peaks of metabolites appeared on the HPLC chart of the cultured broth. DBP was degraded almost $100 \%$ on day 5 , and the metabolites (peaks 1-3) increased slightly as DBP decreased, then they also decreased on day 7, showing further degradation. The peaks 1 and 2 were further separated using a mobile phase of $40 \% \mathrm{CH}_{3} \mathrm{CN}$, where the $t_{\mathrm{R}}$ 's corresponded with those of DMP and MBP, respectively (Fig. 1. HPLC (B)).

Enzymatic Degradation Activity On the enzymolysis 


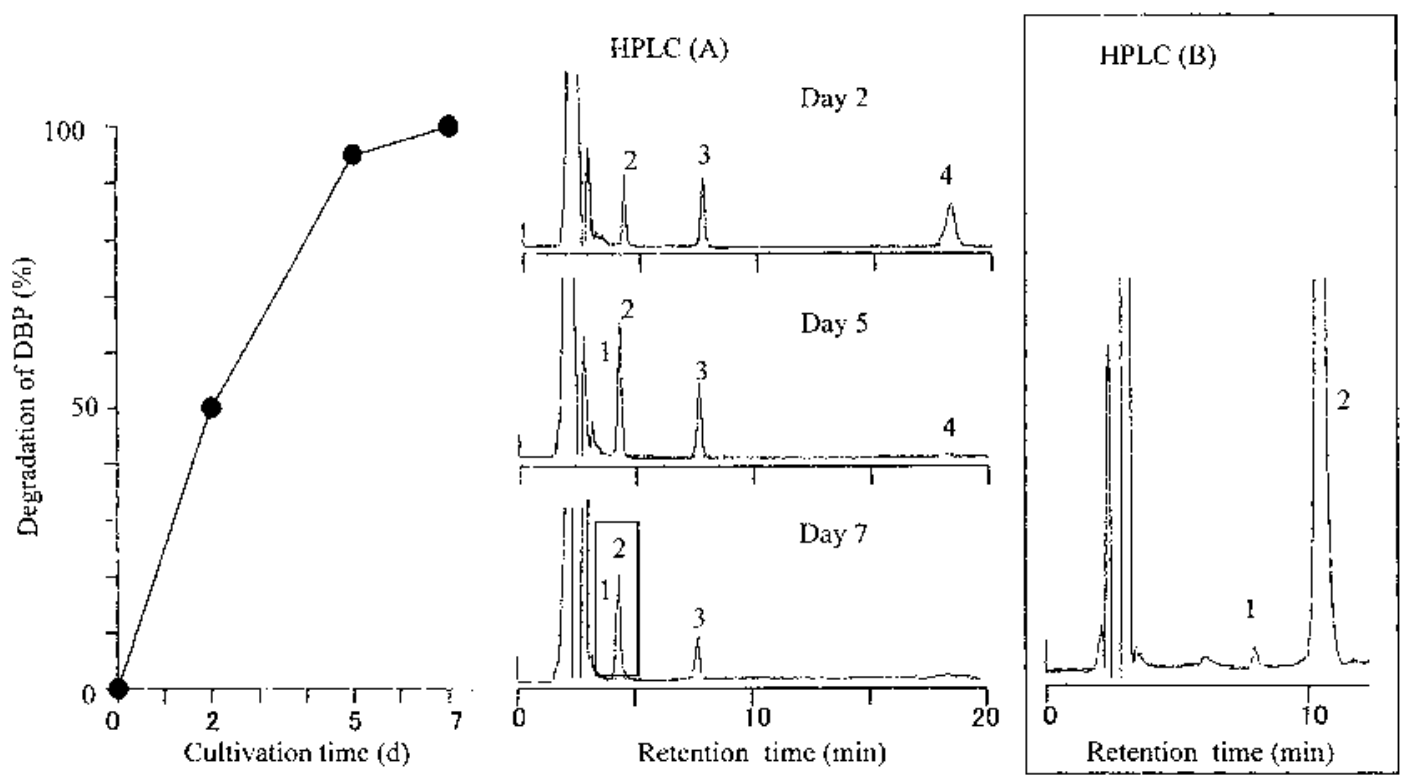

Fig. 1. Time-Courses of DBP Biodegradation by Isolate R3

1, DMP; 2, MBP; 3, unknown; 4, DBP. The area containing peaks 1 and 2 at day 7 in HPLC (A) were further resolved as shown in HPLC (B) under the condition b). DBP (20 $\mu \mathrm{g} / \mathrm{ml})$ was cultured with the isolate R3 in $1 / 10 \mathrm{NB}$. Analytical HPLC conditions: column, Develosil ODS- $5(4.6 \mathrm{~mm}$ i.d. $\times 250 \mathrm{~mm})$; column temperature, $40{ }^{\circ} \mathrm{C}$; flow rate, 1 $\mathrm{ml} / \mathrm{min}$; mobile phases, a) $0.05 \%$ TFA- $60 \% \mathrm{CH}_{3} \mathrm{CN}$ and b) $0.05 \% \mathrm{TFA}-40 \% \mathrm{CH}_{3} \mathrm{CN}$.

Table 6. Degradation of Phthalate Esters by Crude Enzyme Solutions Prepared from Isolates

\begin{tabular}{|c|c|c|c|c|c|c|}
\hline \multirow{3}{*}{ Isolate } & \multicolumn{6}{|c|}{ Enzymatic degradability (nmol/mg protein/min) } \\
\hline & \multicolumn{2}{|c|}{ DEP } & \multicolumn{2}{|c|}{ DBP } & \multicolumn{2}{|c|}{ DEHP } \\
\hline & A & $\mathrm{B}$ & A & $\mathrm{B}$ & A & $\mathrm{B}$ \\
\hline $\mathrm{R} 1$ & 0.01 & 0 & 0 & 0.15 & 0.08 & 0.19 \\
\hline $\mathrm{R} 2$ & 0.05 & 0 & 0.07 & 0.05 & 0.26 & 0.28 \\
\hline R3 & 0 & 0 & 0.13 & 0.18 & 0.12 & 0.22 \\
\hline R6 & - & - & 0 & 0.54 & 0.55 & 0.58 \\
\hline R7 & - & - & 0 & 0 & 0.71 & 1.05 \\
\hline D1 & - & - & 0 & 0.22 & 2.44 & 2.93 \\
\hline
\end{tabular}

Reactions were performed in the presence (A) and absence (B) of the NADPH generating system or the NADH+NADPH. Isolates R1-R3 were incubated at $37^{\circ} \mathrm{C}$ for 30 min with the NADPH generating system, isolates R6, R7 and D1 at $37^{\circ} \mathrm{C}$ for $2 \mathrm{~h}$ with the NADH+NADPH. Isolates R1-R3 and D1: Acinetobacter lwoffii, isolate R7: Pseudomonas alcaligenes.

of PEs by crude enzyme solutions, their degrading activities were higher for DEHP than for biodegradable DBP. Particularly, enzyme solutions from the isolates D1 and R3 showed high DEHP- and DBP-degrading activities, respectively (Table 6). Enzymolysis of PEs by crude enzyme solutions did not necessarily require NADPH or NADH.

Metabolites in Biodegradation Tests and Enzymatic Degradation The metabolites in biodegradation and enzymolysis of PEs by the isolate R3 were separated by preparative HPLC. To detect diester form metabolites, an aliquot of each metabolite fractionated by HPLC was directly applied to GC. Monoester form metabolites in the remainder were converted to diesters by methyl-esterification, then applied to GC. Each monoester metabolite was thus confirmed by the detection of its diester form on GC.

From the biodegradation test, three fractions in addition to DEP were obtained by HPLC from the broth cultured with DEP, and fraction 2 was consistent with DMP on GC. Frac-
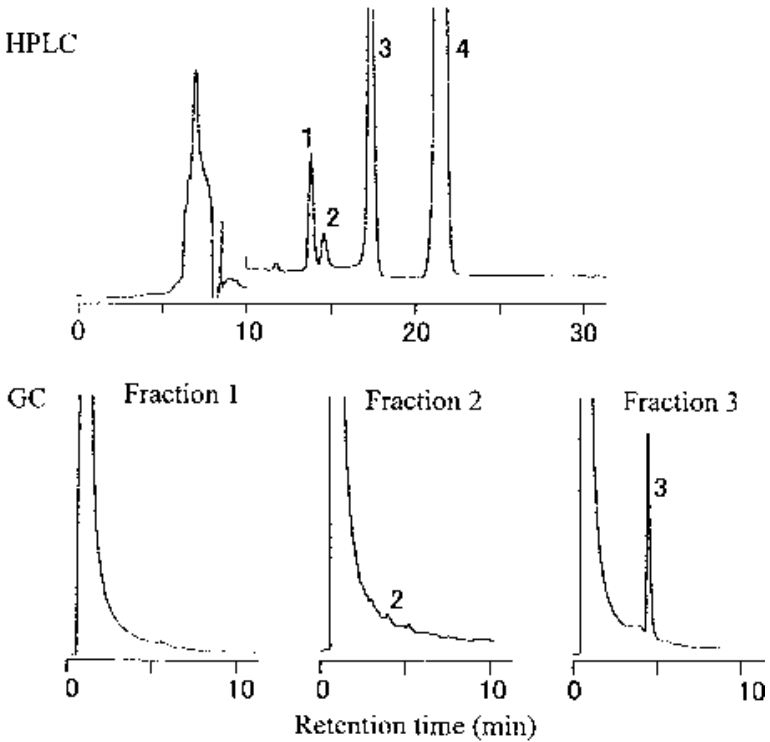

Fig. 2. Preparative HPLC Profile of DEP Metabolites by Isolate R3 and GC Profiles of the HPLC Fractions

1, unknown; 2, DMP; 3, unknown; 4, DEP. Each fraction from the preparative HPLC was collected then applied to GC. HPLC conditions: column, Wakosil $10 \mathrm{C} 18(10 \mathrm{~mm}$ i.d $\times 250 \mathrm{~mm}$ ); column temperature, $40{ }^{\circ} \mathrm{C}$; mobile phase, $0.05 \%$ TFA- $-60 \% \mathrm{CH}_{3} \mathrm{CN}$; flow rate, $2 \mathrm{ml} / \mathrm{min}$. GC conditions: column, silicone OV-17 5\% Uniport HP 80/100 glass $(3 \mathrm{~mm}$ i.d. $\times 2 \mathrm{~m})$; column temperature, $190^{\circ} \mathrm{C}$; injector and detector temperatures, $210^{\circ} \mathrm{C}$; detector, FID.

tion 3 is considered a phthalate diester which was detectable by GC, although its chemical entity has not been confirmed yet (Fig. 2). In the broth cultured with DBP, 4 metabolites (DEP, DMP, MBP, MMP) were detected, and another unknown metabolite was considered a diester derivative (Fig. 3 ). In the broth of DEHP, 3 metabolites (DBP, DEP, DMP) were detected (Fig. 4). The peak 4 on HPLC profile (Fig. 4) is considered same diester derivative since an unknown DBP metabolite was in good agreement with the peak 4 on HPLC 

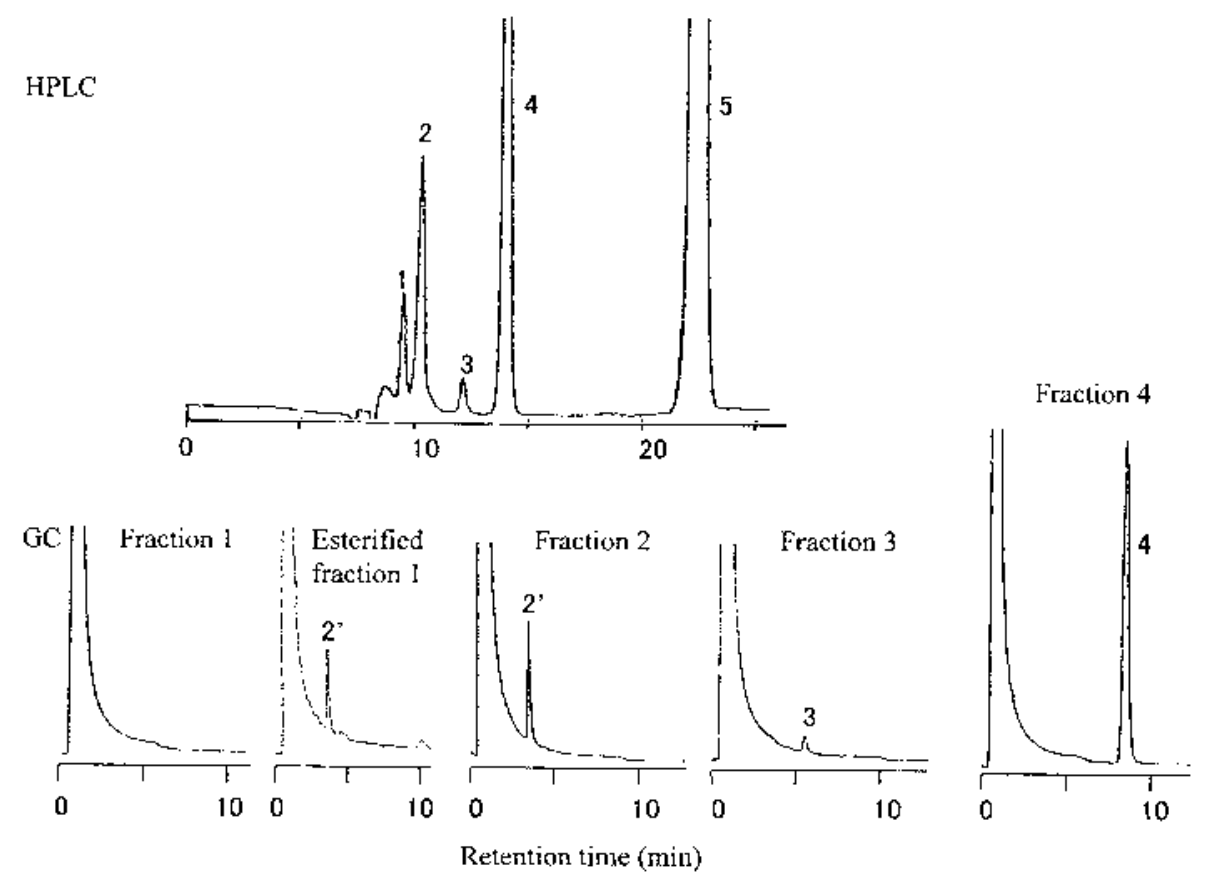

Fig. 3. Preparative HPLC Profile of DBP Metabolites by Isolate R3 and GC Profiles of the HPLC Fractions

1, MMP; 2, DMP and MBP; 2', DMP; 3, DEP; 4, unknown; 5, DBP. Each fraction from the preparative HPLC was collected then applied to GC before or after esterification. HPLC and GC conditions are same as those in the legend of Fig. 2 except mobile phase of $0.05 \%$ TFA- $80 \% \mathrm{CH}_{3} \mathrm{CN}$.
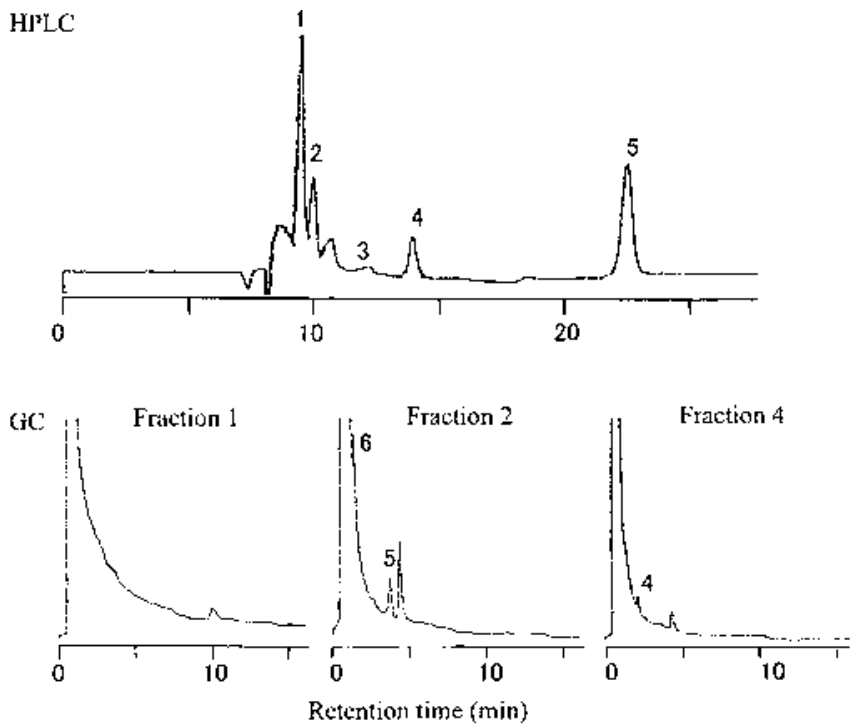

Fig. 4. Preparative HPLC Profile of DEHP Metabolites by Isolate R3 and GC Profiles of the HPLC Fractions

1 and 2, unknowns; 3, DEP; 4, unknown; 5, DBP; 6, DMP. Each fraction from the preparative HPLC was collected then applied to GC. HPLC and GC conditions are same as those in the legend of Fig. 3 except GC column (HP $60 / 80,240^{\circ} \mathrm{C}$ ), injector and detector temperatures $\left(260^{\circ} \mathrm{C}\right)$.

of Fig. 3. In the enzymolysis of PEs, the production of DMP and MBP were confirmed in the reaction with DBP (Fig. 5). The unknown contained in peak 3 in Fig. 5A, corresponded to the unknown diester metabolite in microbial degradation of DBP on HPLC and GC analyses. DBP and MEHP were detected in the enzyme reaction with DEHP as shown in Fig. 5C. Based on the results, the metabolites produced from PEs by the bacterial isolate R3 is summarized as follows: DBP, a
DBP-derived unknown diester, DMP and MEHP from DEHP; DEP, the unknown diester, DMP and MBP from DBP; DMP and the unknown diester from DEP.

PEs were shown to be relatively degradable in the activated sludge systems ${ }^{17,18)}$ and in the aquatic microbial degradation tests. ${ }^{19-21)}$ In this study, a high PE degradation activity was observed in the Tempaku River water by the Handai Method. ${ }^{14)}$ Also, among the isolates tested, many microbes of Acinetobacter sp. showed degradation activities.

The isolates did not degrade DMP, having the shortest carbon chain, while the enzyme solutions showed only slight DEP-degrading activities. The degrading activities of the bacteria were higher for DBP compared with other PEs tested, while the enzymatic degrading activities were highest for DEHP in three PEs (DEP, DBP, DEHP).

The major metabolic pathway of DEHP in animals is hydrolysis of one ester of DEHP by nonspecific lipases, producing MEHP and ethylhexanol, followed by conjugation, or $\omega$ or $\omega$-1 oxidation of the alkyl chain producing 20 types of monoester derivatives. ${ }^{2-26)}$ A degradation pathway in Pseudomonas sp. was reported, ${ }^{20)}$ in which DBP was degraded to phthalic acid via MBP and then to protocatechuic acid. In this study, on biodegradation and enzymolysis using Acinetobacter sp., DBP was produced as a metabolite of DEHP, whereas DMP, an unknown diester and monoester MBP were produced from DBP. Based on our results, there are two or more degradation pathways, where alkyl chains in diester forms are decomposed in addition to the production of monoester at the first step on the biodegradation of DBP or DEHP by aquatic microbes in the environment. To clarify the pathways, further identification of key metabolites including the unknown diesters mentioned here is required. 


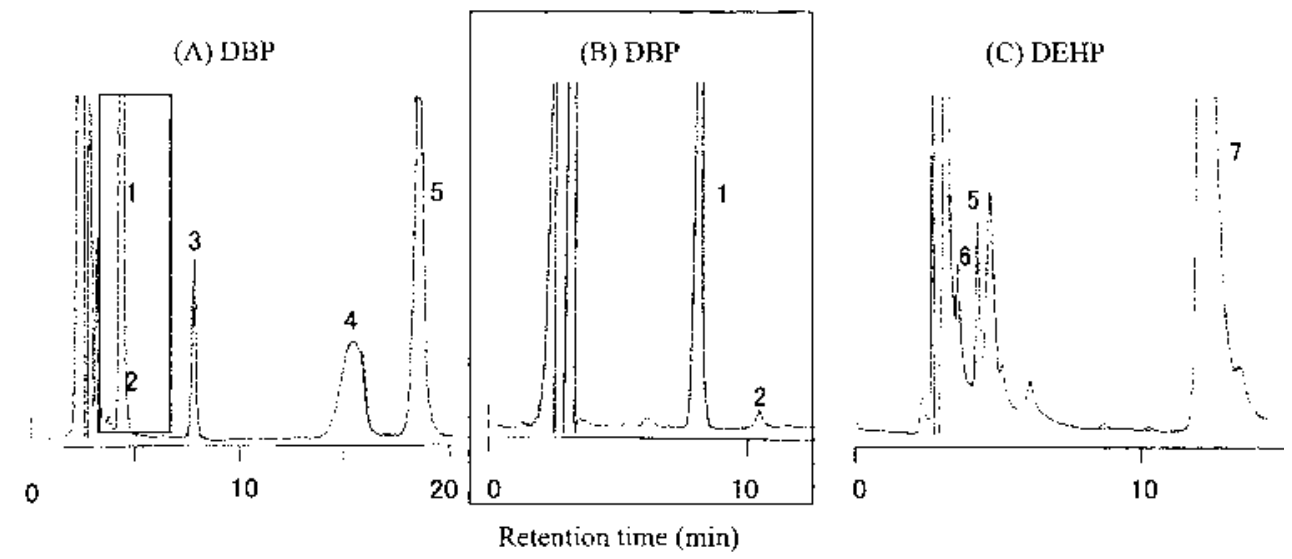

Fig. 5. Analytical HPLC Profiles of DBP and DEHP Metabolites by Enzyme Solution Prepared from Isolate R3

1, DMP; 2, MBP; 3 and 4, unknowns; 5, DBP; 6, MEHP; 7, DEHP. The area containing peaks 1 and 2 in (A) was further resolved as shown in (B) under the HPLC conditions of mobile phase $0.05 \%$ TFA $-40 \% \mathrm{CH}_{3} \mathrm{CN}$. Other HPLC conditions are same as those in the legend of Fig. 1 except mobile phases, $0.05 \%$ TFA- $90 \%$ CH $\mathrm{CN}_{3}$ for $(\mathrm{C})$.

\section{REFERENCES}

1) Nakamura Y., Tomita I., Jpn. J. Toxicol. Environ. Health, 33, $71-89$ (1987).

2) Lake B. G., Gangolli S. G., Grasso P., Lloyd A. G., Toxicol. Appl. Pharmacol., 32, 355-367 (1975).

3) Ohishi S., Hiraga K., Toxicol. Appl. Pharmacol., 53, 35-41 (1980).

4) Singh A. R., Lawrence A. R., Autian J., J. Pharm. Sci., 61, 51-55 (1972).

5) Yagi Y., Nakamura Y., Tomita I., Tsukikawa K., Shimoi N., J. Environ. Pathol. Toxicol., 4, 433-544 (1980).

6) Kluwe W. M., Haseman J. K., Douglas J. F., Huff J .E., J. Toxicol. Environ. Health, 10, 797-815 (1982).

7) Harris C. A., Henttu P., Parker M. G., Sumpter J. P., Environ. Health Perspect., 105, 802-811 (1997).

8) Nishihara T., Nishikawa J., Kanayama T., Dakeyama F., Saito K., Imagawa M., Takatori S., Kitagawa Y., Hori S., Utsumi H., J. Health Sci., 46, 282-298 (2000).

9) Jobling S., Reynolds T., White R., Paker G. M., Sumpter P. J., Environ. Health Perspect., 103, 582-587 (1995).

10) Norrgren L., Blom A., Andersson P. L., Börjeson H., Larsson D. G. J., Olsson P.-E., Aquatic Ecosystem Health and Management, 2, 331317 (1999).

11) "Surveillance of Endocrine Disrupters at Public Water Areas," by Water Quality Management Division, Environment Agency, 1999.

12) Hashizume K., Toda C., Yasui T., Nagano H., Environ. Sci., 12, 41-
49 (1999).

13) Hashizume K., Toda C., Yasui T., Nagano H., Environ. Sci., 10, 233 243 (1997).

14) Kondo M., Nishihara T., Shimamoto T., Watabe K., Fujii M., Jpn. J. Toxicol. Environ. Health, 34, 115-122 (1988).

15) "Method of Analysis in Health Science," ed. by the Pharmaceutical Society of Japan, 2000, pp. 757-758.

16) "Method of Analysis in Health Science," ed. by the Pharmaceutical Society of Japan, 2000, pp. 461-462.

17) O'Grady D. P., Howard P. H., Werner F., Appl. Environ. Microbiol., 49, $443-445$ (1985).

18) Wang J., Liu P., Qian Y., Environ. Int., 22, 737-741 (1996).

19) Zhang G., Reardon K. F., Biotechnol. Lett., 12, 699-704 (1990).

20) Wang J., Liu P., Qian Y., Chemosphere, 31, $4051-4056$ (1995).

21) Wang J., Liu P., Qian Y., Environ. Int., 23, 775-782 (1997).

22) Albro P. W., Thomas R., Fishbein L., J. Chromatogr., 76, 321-330 (1973).

23) Albro P. W., Hass J. R., Peck C. C., Odam D. G., Corbett J. T., Baley F. J., Blatt H. E., Barrett B. B., Drug Metab. Dispos., 9, 223-225 (1981).

24) Albro P. W., Jordan S. T., Schroeder J. L., Corbett J. T., J. Chromatogr., 244, 65-79 (1982).

25) Albro P. W., Tondeur I., Marbury D., Jordan S., Schroeder J., Corbett J. T., Biochim. Biophys. Acta, 760, 283-292 (1983).

26) Kluwe W. M., Environ. Health Perspect., 45, 3-10 (1982). 